\title{
Fundamentality and Modal Freedom
}

Jennifer Wang

\section{Introduction}

The notion of fundamentality has been much discussed recently. The picture is that there is a fundamental level of the world, and that non-fundamental, or derivative, features of the world depend upon the fundamental. My focus in this paper is on a specific question about the nature of fundamentality. Many agree that if an entity is fundamental, then it is in some sense ontologically independent. ${ }^{1}$ This is accompanied by intuitions that it is 'selfsufficient', or 'need not look outside itself'. It is commonly believed that as such, fundamental entities are modally free, in a sense to be clarified. ${ }^{2}$ Intuitively, a mark of modal freedom is some form of free recombination: For each of the various ways modally free entities can individually be, they can be those ways with each other.

The claim that fundamentality entails modal freedom (FEMF) may seem attractive. After all, if an entity 'need not look outside itself', how could it modally depend on anything else? Nonetheless, the road from fundamentality to modal freedom is not straightforward. Some philosophers endorse views that are incompatible with FEMF. For instance, on causal essentialism, fundamental properties are essentially dispositions, powers, or potentialities to manifest certain states of affairs, which include the instantiation of other fundamental properties. $^{3}$ There are thus modal connections between fundamental properties. Other apparent counterexamples to FEMF stem from the supposition that what's fundamental is determined by ideal physics. The properties and relations countenanced by our best current physical theories include quantitative properties and relations such as mass, charge, and spatiotemporal distance. But it is well-known that determinates of the same determinable are incompatible with each other (e.g. mass 50g and mass 60g), and that spatiotemporal relations obey certain metric constraints, and thus modal constraints; call this view incompatibilism. ${ }^{4}$ Finally, the phenomenon of non-separability of entangled states in quantum mechanics yields a view on which there may be necessary connections between fundamental objects. ${ }^{5}$

My aim is not to assess these competing views, about which much has been written. Rather, I will examine the positive reasons that a defender of FEMF may give in favor of her thesis. I begin the next section by saying more about the notion of fundamentality and the relevant types of fundamental entities. In section 3, I give a more careful characterization of modal freedom. I then examine reasons to believe FEMF by way of 'direct' and 'indirect' routes in sections 4 and 5 . Direct routes appeal to the supposed nature of fundamentality, whereas indirect routes make use of principles that appear to be motivated for

\footnotetext{
${ }^{1}$ I will be using the term 'entity' liberally to apply to the purported members of different ontological categories, which may include objects, properties, relations, facts, or states of affairs.

2 This notion is borrowed and adapted from Schaffer (2010a).

${ }^{3}$ For just a few examples, see Bird (2007), Shoemaker (1980), and Vetter (2015). An overview of recent defenders is presented in Vetter (2011).

${ }^{4}$ See Jubien (2009) and Wang (2013).

${ }^{5}$ Schaffer (2010c) takes such phenomena to show that such states aren't fundamental, but his argument appeals to FEMF. Paul (2012, Forthcoming) appeals to quantum phenomena to argue for her mereological bundle theory, which is plausibly extended into a view on which there are necessary connections between fundamental properties.
} 
independent reasons, such as Hume's dictum that there are no necessary connections between distinct existences. I argue that none of these routes provide motivation for FEMF beyond the intuitions that fundamental entities are 'self-sufficient' or 'need not look outside themselves'. In fact, as I will suggest in section 6 , there are positive reasons to hold that the fundamental entities are not modally free.

\section{Fundamentality}

There are many different ways to understand fundamentality. Some connect the notion of fundamentality to other notions, such as grounding, truthmaking, naturalness, structure, or reality. Others take the notion of fundamentality to be primitive, conceptually basic, or otherwise undefinable. This section will be a brief overview of various options. My aim is not to endorse any particular theory of fundamentality, but to show that fundamentality-like notions figure in a range of current metaphysical debates. The reader who is already convinced of this may move on to section 3.

First, consider the notion of grounding, which is a notion of ontological dependence. ${ }^{6}$ This notion of dependence is distinct from the notions of causal, counterfactual or modal dependence. For instance, Sonia Sotomayor grounds her singleton set, but she does not cause it to exist. Some have tried to explain the notion of grounding using other notions. ${ }^{7}$ Whether or not this project eventually succeeds, many agree that grounding has certain features: It is irreflexive, asymmetric, and transitive, and there is a distinction between full and partial grounding. ${ }^{8} \mathrm{~A}$ fundamental entity, on this view, is an ungrounded entity: one that does not ontologically depend on anything else. ${ }^{9}$

\footnotetext{
${ }^{6}$ For surveys on this topic, see Clark and Liggins (2012), Correia and Schneider (2012), and Trogdon (2013a). I will assume that grounding is a category-neutral relation that holds between entities. Some restrict it to facts so that, for instance, the fact that Sonia Sotomayor exists grounds the fact that her singleton exists; see Audi (2012a, 2012b)—though he denies existence facts—and Rosen (2010). Facts in this context are typically understood to be more like states of affairs, that is, objects instantiating properties and relations. Others say that grounding should be characterized as a sentential connective, as in: 'The singleton containing Sonia Sotomayor exists because Sonia Sotomayor exists'; see Correia (2010) and Fine (2012). The connective view is neutral on whether or not 'because' picks out a relation. Thus, one may insist that some truths hold in virtue of other truths, but deny that these may be traced to grounding relations between entities. In fact, some hold that ontological dependence and grounding come apart; see Barnes (Forthcoming). Koslicki (2013a, $2013 \mathrm{~b}$ ) connects the notion of ontological dependence to essence and substancehood.

${ }^{7}$ See discussions in Bennett (2011a), deRosset (2013), and Sider (2011).

8 There is disagreement about whether grounding has these features; see Barnes (Forthcoming), Donaldson (Forthcoming), Jenkins (2011), Kleinschmidt (2015), Litland (2013), Raven (2013), Rodriguez-Pereyra (Forthcoming), Schaffer (2012), and Wilson (2014b). Strictly speaking, Barnes distinguishes ontological dependence from grounding, and she takes her comments to apply to the former only. However, the cases she presents could be modified to apply to grounding, if one were so inclined. Note that partial grounding may be defined in terms of full grounding but not vice versa; see Fine (2012).

${ }^{9}$ Bennett (2011b, Forthcoming) appeals to what she considers to be a broader notion, that of building. On her view, fundamentality is a notion of ontological independence that may be defined in terms of building, so that what is fundamental is unbuilt. Building relations include not just grounding, but also composition, constitution, set formation, realization, microbased determination, and causation. Bennett thus rejects that distinction between ontological and causal independence. Wilson (2014b) counts many of the same relations among what she calls 'small-g' grounding relations. Both deny the existence of a univocal dependence relation that is more fundamental than the individual relations.
} 
Second, fundamentality may be understood in terms of truthmaking, a relation between truths and the entities in the world that make them true. ${ }^{10}$ Truthmaking is generally agreed to be irreflexive, non-symmetric, and non-transitive. Some have explained truthmaking in terms of other notions, such as entailment, necessitation, or essence. ${ }^{11}$ What matters in this discussion is the apparent connection between truthmakers and fundamentality. Arguably, the fundamental entities are those that jointly comprise the truthmakers for all truths that have truthmakers. ${ }^{12}$

Third, consider Lewis's (1983) notion of naturalness. Lewis holds that the property structure of the world is ordered according to more or less natural properties. At bottom, there are the perfectly natural properties, those that 'carve reality at the joints'. These are presumably the properties countenanced by fundamental physics. Lewis argues that we should accept the distinction between natural and unnatural properties given the theoretical work naturalness can do, including:

(i) characterizing notions such as duplication, similarity, intrinsicality, and supervenience;

(ii) determining a supervenience basis for all other properties; and

(iii) formulating theses concerning physicalism, simplicity, and the laws of nature. ${ }^{13}$

Sider (2011) extends the utility of the notion of naturalness by positing a primitive notion of structure; on his account, not only may predicates be structural, other logical particles such as quantifiers and connectives may be structural as well. While Sider theorizes in linguistic terms, structure is worldly. One may say thus say that the fundamental entities just are the perfectly natural or structural entities. ${ }^{14}$

Fourth, one might take the position that the notion of fundamentality is primitive, conceptually basic, or undefinable. Wilson $(2014 \mathrm{~b}, 26)$ suggests that there is something inappropriate about characterizing the notion of fundamentality in terms of any other notion, whether positive or negative. Fine $(2001,25-6)$ explicitly takes the notion of reality to be primitive. (Note that Fine also posits a primitive notion of ground, so that by 'real' he does not simply mean 'ungrounded'.) And Barnes (2012) takes fundamental to be primitive, as well as distinct from ontologically independent.

My aim in gesturing at these various notions is not to canvass the ways in which they are similar and dissimilar. A complete catalogue of the various ways philosophers have talked about fundamentality would be an interesting and worthwhile project, but is simply not feasible here. I only claim to have provided evidence that many philosophers seem to have latched on to some notion of fundamentality. Furthermore, they seem to talk

\footnotetext{
${ }^{10}$ Defenders of truthmaking include Armstrong (2004), Bigelow (1988), Cameron (2008, 2010b), Fox (1987), Lowe (2006, 2009), Mulligan, Rodriguez-Pereyra (2006b), and Mulligan, Simons and Smith (1984). See Rodriguez-Pereyra (2006a) for a survey of this topic.

11 See Armstrong (1997), Bigelow (1988), Fox (1987), and Lowe $(2006,2009)$.

12 See Cameron (2008, 2010b) and Schaffer (2008).

${ }^{13}$ The claim that one class of properties may play all of these different theoretical roles is challenged in Dorr and Hawthorne (2013).

${ }^{14}$ Sider himself thinks there are serious limitations to talk of structural entities rather structural ideology; see 6.3 of his book. For further discussion of naturalness, including skepticism that one such notion plays all of the naturalness roles, see Dorr and Hawthorne (2013) and Eddon (2013).
} 
about such a notion univocally, even if it is far from clear that the same fundamental entities that play, e.g., the truthmaker role also play the naturalness role. ${ }^{15}$ I will thus proceed as if there is one notion of fundamentality in question.

There are various categories of entities that may be fundamental; the two I will focus on are object and property or relation. ${ }^{16}$ Much of the discussion below applies to other candidates for fundamentality, such as fact or state of affairs. I will start by assuming that fundamentality is category-relative, so that an entity may be fundamental in its own category even if it ultimately depends on an entity in a different category.

\section{Modal freedom}

What does it mean for a fundamental entity to be modally free? For those who work with the ideology of grounding, there is a relatively uncontroversial claim in the vicinity of FEMF, called 'necessitarianism': If $x$ (fully) grounds $y$, then necessarily, if $x$ exists then $y$ exists. ${ }^{17}$ Necessitarianism on its own does not entail FEMF; it only tells us that grounded entities are, in some sense, not modally free. But it does provide a suggestion for how to characterize modal freedom. Say that an entity $\mathrm{x}$ is absolutely existentially modally free iff it is not the case that there is some distinct entity y such that necessarily, if $y$ exists then $x$ exists, or necessarily, if $\mathrm{x}$ exists, then $\mathrm{y}$ exists. This principle tells us that $\mathrm{x}$ is modally free in some sense just in case its existence neither is necessitated by nor necessitates the existence of any other entity.

Unfortunately, absolute existential modal freedom is not the most useful notion to work with. Every entity is such that necessarily, it exists iff its singleton set exists, even though the grounding relation holds in only one direction. ${ }^{18}$ From this mundane observation it follows that no entity is absolutely existentially modally free. Furthermore, this notion of freedom tells only on existential freedom, even though an entity that must instantiate a certain property under a condition involving a distinct entity also lacks modal freedom in some sense.

The relevant notion of modal freedom is not absolute, but relational. Let's turn to Schaffer (2010a)'s characterization of (the dyadic case of) modal freedom, which I will call 'Schaffer-freedom'. Two concrete objects are Schaffer-free if any way that one can be and any way the other can be is a way for them to jointly be, (i) barring co-location, and (ii) leaving the rest of the world the way it is. On what 'any way that one can be' means, Schaffer writes (2010a, 352): '[C]onsider all of the intrinsic natures that a given actual concrete object can have, together with all of the spatiotemporal locations that it can occupy. These are the ways that this can be. Also add in the one way that it can fail to be. The result will be a list covering the how, where, and whether possibilities for this thing.' Notice the restriction to intrinsic properties of objects. If we allowed 'ways' to range over

\footnotetext{
15 Barnes (2012) and Fine (2001) are exceptions.

16 I will be assuming that properties and relations are abundant, even if we may further classify them into 'sparse' and 'abundant', 'fundamental' and 'derivative', 'natural' and 'nonnatural', etc.

17 This is a simplification of the principle that typically goes under this name. It is often formulated so that the grounds may be a set or plurality, and sometimes it is time-indexed. These details do not matter for this discussion. Necessitarianism is widely assumed, but see deRosset (2010) and Trogdon (2013b) for explicit defenses. For arguments against necessitarianism, see Schaffer (2010b), Schnieder (2006), and Skiles (2015). 18 This is basically Fine's (1994) counterexample to the converse of necessitarianism.
} 
extrinsic properties as well, then given that one way for an object to be is such that some other object does not exist, modal freedom would be too difficult to obtain.

The first qualification, 'barring co-location', is by Schaffer's admission already a modal constraint. Assuming that two concrete objects cannot be co-located, it would be a bad result if two entities could fail to be modally free simply because being located at region $\mathrm{R}$ is a way for each to be independently. The second qualification relativizes modal freedom to the rest of the universe. As Schaffer (2010a, 354) puts it: 'The intuitive idea is that if two actual concrete objects really are [Schaffer-]free of each other, then realizing their combinations should not require alterations to anything distinct. By 'the remainder of the world' I mean the concrete universe minus the sum of the two objects in question, and by 'leaving it as it is' I mean preserving its intrinsic nature and spatiotemporal location, while not adding in any alien properties or individuals.'

Schaffer is only concerned with concrete objects-fundamental or not-in the discussion in which Schaffer-freedom is invoked. In contrast, I'm interested in a notion of modal freedom that applies to other candidates for fundamentality. Furthermore, this notion of modal freedom is relative; we are only concerned with the notion of a fundamental entity's being modally free relative to some class, namely, other fundamental entities. As noted above, no fundamental entity is absolutely existentially modally free, but this is no threat to modal freedom. ${ }^{19}$ I will start by assuming that modal freedom is category-relative, so that an entity may be modally free in its own category even if it is modally free of an entity of a different category. This aligns with the starting assumption of fundamentality as category-relative. Cross-category modal freedom must be addressed eventually, but category-relative fundamentality is still useful as a starting point. I will later take consider cross-category modal freedom.

First, let $\Gamma$ be the set of fundamental objects, and let 'ways an object can be' range over the intrinsic properties that an object may have, in addition to existence or nonexistence. Following Schaffer's lead: $\Gamma$ is modally free iff for any ways that any objects in $\Gamma$ can be, they may respectively be those ways. A merely dyadic notion of freedom cannot account for cases where two fundamental properties $\mathrm{x}$ and $\mathrm{y}$ require that a third have some property in order for $\mathrm{x}$ and $\mathrm{y}$ to jointly be some way. (Schaffer himself extends his characterization to variably polyadic cases of modal freedom.) The present characterization relativizes freedom to the set of all fundamental objects. As such, the qualification 'leaving the remainder of the world as it is' must be dropped. This is because changes in the properties of fundamental objects may lead to changes in derivative objects, but this does not seem to be a problem for the modal freedom of fundamental objects. I am also ignoring the issue of co-location. I agree with Schaffer that banning co-location is already a modal constraint, and should thus not be built into the characterization of modal freedom.

Second, let $\Gamma$ be the set of fundamental properties and relations. If we mimic the case of objects, we get this: $\Gamma$ is modally free iff for any ways that any properties or relations in $\Gamma$ may be, they may respectively be those ways. On this formulation, what matters are intrinsic properties of properties or relations, or their existence or nonexistence. But it is not clear that there are interesting contingent intrinsic properties of

\footnotetext{
${ }^{19}$ It worth noting that Zimmerman (Forthcoming) takes issue with Schaffer's characterization of modal
} freedom. Restricting our attention to fundamental entities avoids many of these issues. 
properties or relations; necessary intrinsic properties, such as being a property or being a relation, must be instantiated. It may be that some properties only exist contingently, but this is a substantive and controversial philosophical thesis. In any case, the resulting notion of modal freedom, even if satisfied by the fundamental properties and relations, is still somewhat boring. (Similar difficulties apply to the principle for objects if one believes in fundamental abstract objects.) When it comes to properties or relations, their more interesting features are extrinsic, i.e. how they're intantiated. So a better principle for properties and relations is this: $\Gamma$ is modally free iff any pattern of instantiation of the properties or relations in $\Gamma$ is possible. This avoids the issue with co-location since properties may co-exist in the same object. And for similar reasons as in the objects case, it avoids the issue of the 'remainder of the world'. ${ }^{20}$

Many fundamentality theorists seem to have intuitions that support FEMF. Some endorsements are explicit. For instance, Schaffer (2010c, 40) writes, '[A] plurality of entities is freely recombinable if and only if any combination of ways that each entity can be individually is a way that the plurality can be collectively. If entities are metaphysically independent, then they should be modally unconstrained in combination.'21 Other endorsements are less explicit. Many accept a principle of free recombination that takes their fundamental entities as elements of recombination. For instance, Lewis's (1986) perfectly natural properties obey a principle of recombination over points of spacetime. And Armstrong (1989) is sympathetic to a notion of independence for his sparse universals, even if he doesn't entirely commit to FEMF. In any case, he writes approvingly of Wittgenstein's (1921/1961) freely recombinable atomic states of affairs. There are also fundamentality theorists who do not discuss the question, or are outright committed to rejecting FEMF. (See section 6.) But it is clear that FEMF is widely endorsed, if not universally accepted, and is worthy of careful examination.

\section{Direct routes to FEMF}

In this section, I consider direct routes to FEMF. The goal will be to examine reasons in favor of FEMF that stem from the supposed nature of fundamental entities.

\subsection{The intuitions}

As noted, many theorists seem to endorse FEMF on the basis of the intuition that whatever is fundamental is 'self-sufficient', or 'need not look outside itself'. The appeal to intuitions can be a useful first step in theorizing about a metaphysical notion, for intuitions may clarify what work a notion is intended to do. However, these intuitions do not decisively yield FEMF. If fundamentality is a notion of ontological independence, then the intuition that fundamental entities are in some sense self-sufficient is unsurprising. But it is not clear what else follows from this claim. A self-sufficient person can take care of her own basic needs without the interference of others. A self-sufficient homestead contains its own

\footnotetext{
20 These formulations of modal freedom - for objects and for properties and relations-are independent of each other. I am inclined to think that the characterization of modal freedom for properties and relations is the one that generalizes to other candidates for fundamental categories of entities, e.g. facts or states of affairs. This is because the intrinsic properties of these entities don't appear to be modally malleable. In contrast, the intrinsic properties of objects are, unless one accepts something like mereologically essentialism in the case of concrete objects.

21 See also Bennett (2011a, Forthcoming) and Schaffer (2003, 2010a).
} 
source of production for its main needs, such as food, energy, and household materials. A self-sufficient economy does not require external trade. There is a common theme of freedom from external influences in these examples. But this kind of freedom is already contained in the notion of ontological independence in the case of fundamental entities. And crucially, ontological independence is not modal independence. After all, the theories of fundamentality discussed in section 2 are stated without the assumption of FEMF.

If the intuition that what's fundamental is 'self-sufficient' supports FEMF, then it should at least be acknowledged that this is mere intuition. But there remains a problem. The intuitions that underlie FEMF are undermined given the possibility of fundamental entities of different categories. The restriction in the characterization of modal freedom to different categories of entity is already a constraint. If fundamental properties and relations 'need not look outside themselves', and fundamental objects 'need not look outside themselves', then they should be free to coexist with each other in any combination. But this is not the case. Objects can only instantiate properties and relations, and indeed cannot exist without instantiating properties or relations. Likewise, properties and relations can only be instantiated by objects.

Of course, I have not yet articulated a category-neutral principle for FEMF that such cases violate. This task is not straightforward. I arrived at the principles for objects and for properties and relations in part by considering how they are thought to interact with each other. Objects have properties and stand in relations, and these in turn are instantiated by objects. Other candidates for categories of fundamental entities may require their own principles depending on the ways that they may be. Suppose, for instance, that there are fundamental states of affairs. States of affairs may be said to have objects, properties, or relations as constituents. So perhaps a way for a state of affairs to be is for it to have suchand-such objects, properties, or relations as constituents, and perhaps it is contingent whether it exists. However, it does not seem like the resulting principle is plausible: where $\Gamma$ is the class of fundamental states of affairs, $\Gamma$ is modally free iff for any ways that any states of affairs in $\Gamma$ can be, they can respectively be those ways. This is not plausible because fundamental states of affairs that share constituents arguably are not modally free of each other. The prospects seem dim for a category-neutral principle for defenders of FEMF.

But this does not mean that the problem of cross-category modal freedom disappears. In fact, that the principles are hard to formulate is evidence that we have deeply entrenched views about how entities from different ontological categories must relate to each other. Although it is conceivable, in the abstract, that there are distinct fundamental ontological categories such that the entities in each stand in only trivial relations to each other (e.g. co-existence), the categories actually invoked are not like this. I thus reiterate: if 'self-sufficiency' truly is the motivation for FEMF, then the FEMF theorist should say that there is at most one category of fundamental entities.

One may deny that there are fundamental entities of different categories by endorsing a one-category ontology. For instance, one may endorse a 'properties-first' view, on which facts about objects are reducible to facts about distributions of properties and relations. ${ }^{22}$ Alternatively, one may endorse an 'objects-first' ontology, perhaps accepting a version of nominalism about properties and relations. I do not object to such views per se.

${ }^{22}$ For discussion in the fundamentality literature, see Dasgupta (2009) and Paul (2012, Forthcoming). 
However, such views involve commitments not yet undertaken by many fundamentality theorists.

\subsection{The explanatory independence of the fundamental}

In any case, the first route to FEMF is no more than mere intuition. Can the defender of FEMF provide reasons based on more substantive considerations about the nature of fundamentality? Here's a second route to FEMF that appeals to the connection between ontological independence and a distinctively metaphysical form of explanation. The reasoning goes something like this: Fundamentality is a sort of explanatory independence. So if $\mathrm{x}$ is fundamental, then the explanation for its existence must not require anything extrinsic to $\mathrm{x}$.

But this alone doesn't show that FEMF is true. After all, we've merely put the claim that $x$ is fundamental another way. When we say that the explanation of $x$ 's existence does not require anything extrinsic to $x$, we are merely saying that nothing outside of $x$ contributes to the metaphysical explanation of its existence. This does not entail that x's existence does not necessitate the existence of anything else, nor that nothing else necessitates x's existence. The above considerations about fundamental entities of different types may provide an example of how there could be necessary connections between fundamental entities that are nonetheless explanatorily independent, as one may insist that the existence of fundamental objects is not explained by the existence of fundamental properties, nor vice versa. ${ }^{23}$

\section{Indirect routes}

In this section, I examine indirect routes to FEMF, those on which FEMF follows from the application of a principle that appears to be independently motivated.

\subsection{Hume's dictum}

The main 'indirect' route proceeds via Hume's dictum, a principle endorsed by many independently of discussion of FEMF. Hume's dictum is typically formulated like so: There are no necessary connections between distinct existents. ${ }^{24}$ Though it is inspired by Hume, the various contemporary formulations do not aim to be faithful to Hume himself. For instance, even though Hume was discussing necessary connections in the context of causation, contemporary formulations typically do not limit themselves in this way. The variety of necessity in question is metaphysical, rather than causal, physical, deontic, conceptual, or some other variety.

If there are no necessary connections between distinct existents, then any way an existent can be is (with minor qualifications) compossible with any way a distinct existent can be. And if fundamental entities are distinct existents, then it seems like there's a fairly straightforward route from Hume's dictum to FEMF. However, Hume's dictum is unclear as formulated. For one thing, what is an existent? I will alongside others simply interpret 'existent' as 'entity'. But one may think Hume's dictum applies to only some subclass of entities one believes in, such as concrete objects.

\footnotetext{
${ }^{23}$ In any case, I suspect that the connection between modality and explanation requires much closer examination in order for this route to FEMF to get off the ground. A good starting place is Kment (2014). ${ }^{24}$ For thorough examination of Hume's dictum in recent literature, see Wilson (2010, 2014a, 2015).
} 
A second issue is that it is not clear what is meant by 'necessary connections'. There appear to be trivial necessary connections between distinct objects. For instance, many accept the necessity of identity and distinctness, which state, respectively, that any object is necessarily identical to itself (so any two objects are necessarily such that each is selfidentical), and any two distinct objects are necessarily non-identical. DeRosset (2009) suggests that we distinguish between necessary relations like these, and necessary connections, though he does not offer a criterion whereby to distinguish them. He (158) writes, 'Difficult as this distinction is to explain clearly, it is as indispensable as it is intuitively compelling.' I don't know if this is right. But it seems sensible to stipulate that objects $\mathrm{x}$ and $\mathrm{y}$ are necessarily connected if some intrinsic property that one instantiates has modal implications for the intrinsic properties that the other instantiates. This aligns the modal independence invoked in Hume's dictum with our notion of modal freedom for objects. Adjustments may be made for the case of properties and relations.

A third issue is that it is not clear what is meant by 'distinct'. A straightforward interpretation is that the sense of distinctness in question is numerical distinctness, e.g. there are no necessary connections between numerically distinct entities. Unfortunately, this leaves us with an implausible principle. Take a bicycle and one of its parts, like its chain. The bicycle is numerically distinct from its chain, but the bicycle (construed as a mereological sum, at least) cannot exist without the chain. So this interpretation of Hume's dictum is false. Many say instead that Hume's dictum does not apply to two entities unless they are 'wholly distinct'. Let's consider some candidate interpretations of 'wholly distinct'.

Here's one option available to those who work with the ideology of grounding. Let 'wholly distinct' mean 'grounding distinct', where two entities $\mathrm{x}$ and $\mathrm{y}$ are grounding distinct iff it is not the case that (i) $\mathrm{x}$ (partially) grounds $\mathrm{y}$, (ii) y (partially) grounds $\mathrm{x}$, or (iii) $\mathrm{x}$ and $\mathrm{y}$ share a common (partial) ground. ${ }^{25}$ Thus:

Grounding distinctness: Entities are wholly distinct just in case they are grounding distinct.

One may believe that the Eiffel Tower and the Washington Monument are each nonfundamental entities, but are grounding distinct. In this case, Hume's dictum would say that there are no necessary connections between the Eiffel Tower and the Washington Monument. This interpretation straightforwardly entails FEMF.

Next, Wilson (2010) suggests these two interpretations:

Spatiotemporal distinctness: Entities are wholly distinct just in case they do not spatiotemporally overlap.

Mereological distinctness: Entities are wholly distinct just in case they do not share a mereological part.

These are each plausible candidates for 'wholly distinct'. ${ }^{26}$

25 This is the notion of distinctness invoked in Ismael and Schaffer (Forthcoming).

${ }^{26}$ Note that Wilson herself does not argue that Hume's dictum leads to FEMF. See Wilson (2012). 
Finally, consider deRosset $(2009,158)$ on the question: 'I will say that two things are wholly distinct if they are not merely numerically distinct, but also "distinct existents" in the intended sense. For instance, sets and their members, sums and their parts, and ordinary physical things and their physical parts provide examples of numerically but not wholly distinct individuals.' To this list, Wilson (2010) adds members of natural kinds and their essential intrinsic properties, and mental states and the physical states that realize them. These examples all invoke varieties of what may be called 'constitutional' relations (which include mereological relations as well). So let's also add:

Constitutional distinctness: Entities are wholly distinct just in case they do not stand in constitutional relations to each other.

With these interpretations in mind, does Hume's dictum provide reason to believe FEMF? As mentioned above, given certain assumptions, the first on its various interpretations entails the second-so in this sense, yes. But my question is more specific. Can one who is antecedently neutral on FEMF use Hume's dictum to justify it? If the truth of an interpretation of Hume's dictum relies on the same intuitions that underlie belief in FEMF-e.g. the intuitions of 'self-sufficiency', or that the entities in question 'need not look outside themselves' - then this version of Hume's dictum is not an independent source of belief in FEMF. For each candidate interpretation of distinctness, there are two questions to consider: (1) are the fundamental objects and properties/relations distinct in this sense?; and (2) is the resulting interpretation of Hume's dictum independently motivated?

First, consider grounding distinctness. It is trivial that any two fundamental entities are grounding distinct, since fundamental entities are ungrounded. Hence the first question is easily answered. But the resulting interpretation of Hume's dictum does not seem independently motivated. The intuition behind the belief that there are no necessary connections between grounding distinct entities might be this: If two entities are grounding-distinct, then they neither ground each other nor share a common ground, so they 'have nothing to do with each other'. In that sense, while they may not be 'selfsufficient' simpliciter, neither requires the other.

Second, consider mereological distinctness, and specifically the case of fundamental objects. Are these mereologically distinct, and is the resulting interpretation of Hume's dictum independently motivated? One may reason as so: If two objects overlap, then they share a part, and it is reasonable to believe that whatever fundamentality structure of the world, things with parts are not fundamental. Schaffer himself rejects this view-on his 'priority monism', the most fundamental concrete object is the entire universe, the cosmos as a whole. But even on priority monism, the one fundamental object does not mereologically overlap with any other fundamental object.

I conjecture that the resulting interpretation of Hume's dictum still comes down to mere intuition. Why believe that there are no necessary connections between mereologically distinct objects? Perhaps one has the intuition that mereologically distinct objects 'have nothing to do with each other'. This appeals to the same intuitions invoked in 
grounding distinctness, and as suggested above, in FEMF. So this interpretation of Hume's dictum is not independently motivated either. ${ }^{27}$

Now consider the case of fundamental properties and relations. Are these mereologically distinct, and is the resulting interpretation of Hume's dictum independently motivated? There is an extra complication in this case, which is that it seems to assume that there are mereological relations between properties. Perhaps one does endorse this view, believing for instance that the property of being red has the property of being maroon as a part. One may then think that the fundamental properties and relations must be mereologically distinct. But the resulting interpretation of Hume's dictum relies on the same intuitions as FEMF, as discussed above. On the other hand, if one believes that all properties and relations are mereologically distinct-perhaps because they are not mereologically related, period-then on the resulting interpretation of Hume's dictum, all properties are modally free of each other, including the property of being red and the property of being maroon. This seems to be the wrong result.

Third, consider spatiotemporal distinctness, and the case of objects. It is not clear that fundamental objects must be spatiotemporally distinct-for if there are such things as extended simples, it may well be that they are fundamental, yet spatiotemporally coincide. One may reject this possibility; but even so, the resulting interpretation of Hume's dictum relies on the same intuitions as FEMF. For why believe it, unless one has the intuition that spatiotemporally distinct objects 'have nothing to do with each other'?

Consider next the case of properties and relations. Are they spatiotemporally distinct, and is the resulting interpretation of Hume's dictum independently motivated? Suppose one believes that properties and relations may have spatiotemporal location, perhaps because they are immanent universals or tropes. In this case, it is implausible that the fundamental properties and relations must be distinct-after all, an object can instantiate more than one property, and stand in multiple relations to other objects. There is no reason to suppose that there is a special restriction when it comes to the fundamental. On the other hand, suppose one denies that properties and relations may have spatiotemporal location. But then a similar problem arises as in the case of mereological distinctness. All properties and relations turn out to be spatiotemporally distinct, including the property of red and the property of maroon, which makes the resulting interpretation of Hume's dictum false.

Finally, consider constitutional distinctness. As this version of Hume's dictum is more general than the previous two, it inherits their problems. Worse, it is not clear that so-called 'constitutional' relations form a similarity class at all. Wilson's (2010) view of what counts as a constitution relation invokes the notion of ontological dependence. For her, constitutional relations are simply those relations that hold between entities that are not wholly distinct. This notion of distinctness does not shed light on what it means for two entities to be wholly distinct.

\subsection{Humean supervenience}

\footnotetext{
27 Part of Lewis's view is that when it comes to concreta, mereologically distinct objects may be freely recombined. This is one of the basic tenets of his metaphysical views. One of Lewis's own complaints about necessary connections between distinct existences is that he finds them 'unintelligible'; see Lewis (1983, 366; 1986a, 181).
} 
Here is another route to FEMF. One might be motivated by a desire to reduce the world to its intrinsic properties. Such a person might have Lewisian intuitions that all global matters of fact may be explained by local matters of fact. Lewis (1986b, ix-x) himself writes:

Humean supervenience is named in honor of the greater denier of necessary connections. It is the doctrine that all there is to the world is a vast mosaic of local matters of particular fact, just one little thing and then another ... We have geometry: a system of external relations of spatiotemporal distance between points. Maybe points of spacetime itself, maybe point-sized bits of matter or aether or fields, maybe both. And at those points we have local qualities: perfectly natural intrinsic properties which need nothing bigger than a point at which to be instantiated. For short: we have an arrangement of qualities. And that is all. There is no difference without difference in the arrangement of qualities. All else supervenes on that.

As this characterization concerns only properties and relations, let's set aside the case of fundamental objects. Let's also grant the viability of Humean supervenience. Part of the doctrine of Humean supervenience is that all contingent facts about a world supervene on the pattern of instantiation of the perfectly natural properties over point-sized objects, along with their spatiotemporal relations. Another part is that all (actual) perfectly natural properties are intrinsic. ${ }^{28}$ The important part, for our discussion, is a modal claim: Any pattern of instantiation of the perfectly natural properties over point-sized objects, along with their spatiotemporal relations, is possible.

It is not clear that the notions of fundamentality and perfect naturalness coincide. While Lewis sometimes uses the term 'fundamental', he does not seem to mean 'ontologically independent'; rather, it seems to be just another way to say 'perfectly natural'. Perfectly natural properties play different theoretical roles when it comes to topics in metaphysics such as similarity, duplication, intrinsicality, physicalism, and the laws of nature. A case can be made that one of these roles is to be ontologically independent. But it is controversial whether these roles are jointly satisfiable. ${ }^{29}$

The defender of FEMF may avoid these difficulties by modifying Lewis's characterization of Humean supervenience so that it invokes fundamental properties rather than perfectly natural properties (even if they ultimately coincide). She may say that all fundamental properties are intrinsic, perhaps by saying that this is just part of the nature of fundamentality. The idea is then that any pattern of instantiation of fundamental properties over point-sized objects, along with their spatiotemporal relations, is possible.

We still need to get from here to FEMF: Any pattern of instantiation of the fundamental properties and relations is possible. Plausibly, fundamental properties are only instantiated by point-sized objects. Let's grant that this is not a problem. But the defender of FEMF must say something about fundamental relations. Relations are typically

\footnotetext{
${ }^{28}$ See Lewis $(1983,357)$; Robinson (1993) holds that fundamental physical properties are paradigmatically intrinsic.

${ }^{29}$ See Dorr and Hawthorne (2013) and Weatherson (2013). Weatherson (2006) argues that there must be non-fundamental perfectly natural properties.
} 
classified as internal or external, where a relation is internal just in case it supervenes on the intrinsic properties of its relata, and otherwise external. The defender of FEMF ought to deny the possibility of fundamental internal relations. After all, an internal relation depends on its relata. If she is to admit fundamental relations at all, they must be external. Lewis himself admits spatiotemporal relations, which are paradigmatically external relations, and builds them into his characterization of Humean supervenience. He is free to say that spatiotemporal relations are perfectly natural without requiring them to be modally free of the perfectly natural properties. But spatiotemporal relations-and other cases of external fundamental relations, if there are any-are problematic for the defender of FEMF. For if spatiotemporal relations are treated separately in the characterization of Humean supervenience, then we cannot get from Humean supervenience to FEMF. ${ }^{30}$

Here is one final point. On the assumption that Humean supervenience is true, it entails FEMF only if there are no fundamental relations. But even if there are no fundamental relations, the defender of FEMF has not identified an independently motivated indirect route to FEMF. Wilson $(2015,141)$ points out Humean supervenience is not too far from Hume's dictum:

The question becomes more pressing upon recognizing that Lewis's specification of the fundamental properties as "intrinsic" doesn't suffice to rule out [necessary connections between wholly distinct entities], though he often speaks as though it does. For a property may be intrinsic, in that its instantiation does not require the existence or instantiation of any other objects or properties ... and yet still be "modally loaded," in that, for example, the property is necessarily such that when instanced in certain circumstances, it (its instance) brings about certain effects. What then prevents the "intrinsic" fundamental physical properties in Lewis's supervenience base from standing in various necessary connections to other (actually or possibly instanced) properties?

This observation shows that the motivation for FEMF based on a fondness for Humean supervenience should really be assimilated into the discussion of Hume's dictum as a motivation for FEMF. And if the arguments of the last section are correct, this means that Humean supervenience does not provide an independent motivation for FEMF.

\subsection{The inductive argument}

A third route to FEMF appeals to a certain explanatory asymmetry between fundamental and derivative entities, and may be framed as an inductive argument. Consider cases where it's clear that two things are necessarily connected. A region of spacetime is necessarily connected to any region contained in it. Necessarily, Sonia Sotomayor exists iff her singleton exists. We may look to examples of the types of entities that are constitutionally related for further examples of necessarily connected entities: sums and their parts, members of natural kinds and their essential intrinsic properties,

\footnotetext{
${ }^{30}$ Michael Della Rocca has pointed out to me that the defender of FEMF might simply accept external relations among her fundamental entities. I agree that this is an available move. But I deny that the most plausible candidates for fundamental relations recombine nicely with the most plausible candidates for fundamental properties.
} 
mental states and their physical realizers. These are cases where one entity is ontologically dependent on another. This suggests an inductive generalization to the conclusion that all cases of necessary connections between distinct entities involve cases where one is ontologically dependent upon another. ${ }^{31}$

The pull of these cases is strong-if these are the only sorts of cases we look at. But consider the views that reject FEMF mentioned in section 1. The causal essentialist thinks there are fundamental properties that stand in necessary causal connections to each other, and the incompatibilist thinks there are fundamental properties that are necessarily incompatible with each other. Another view mentioned holds that there are necessary connections between fundamental particles in an entangled state. We ought not to exclude this evidence outright in order to make the inductive argument work. ${ }^{32}$

\subsection{All-things-considered theoretical virtue}

It may be that neither Hume's dictum nor Humean supervenience provide an independent reason to believe FEMF. But we should not give up on them; they may figure in a different indirect route to FEMF. This route is suggested by Wilson $(2015,155)$ :

[A]t the end of the day there is one other consideration that might lead us to endorse HD, as presupposed by Lewis's account of combinatorialism. While, as I've here tried to show, Lewis's account of combinatorialism has its problems, other accounts also have their problems. And even if on this specific issue Lewis's account, and associated appeal to HD, does not come out ahead, it might be that all things considered Lewis's overall framework motivates HD, as presupposed not just in his account of the space of metaphysical modality but moreover, as we have seen, as presupposed in nearly every important aspect of his systematic philosophy. And so far as the end game of deciding which systematic philosophy is the best, Lewis's views are very much still in the running.

Wilson is talking about Hume's dictum specifically, but her strategy may be extended to FEMF. This is a broad methodological maxim that many philosophers follow: The best theory is that which fares best overall with respect to the theoretical virtues. These may include conservatism, modesty, simplicity, generality, and refutability, as articulated in Quine (1970).

This strategy is arguably the most promising for the defender of FEMF. If FEMF cannot be independently motivated by direct means, then perhaps it can be motivated by its place in the best metaphysical theory. I have no argument against such a strategy per se. But I do think that appealing to theoretical virtue is a mere signal that there may be a problem at the end of the day, and does not justify the rejection of views that violate FEMF.

\footnotetext{
31 Thanks to Ross Cameron for suggesting an inductive argument, and see Cameron (2010a).

32 There is a thorough discussion in Wilson (2015) of the strategy of justifying Hume's dictum by inference to the best explanation. This is a related kind of inductive argument, where the basic idea is that Hume's dictum is justified by its utility in Lewis's combinatorial theory of possibility. Wilson argues that this combinatorial principle undergenerates the space of possibilities, and that the possible fixes are either unprincipled, result in extensional inadequacy, or violate Lewis's reductive ambitions.
} 
The weighing of theoretical virtues is a tremendously complicated project, and as far as I know, no one on either side of FEMF has actually carried it out. ${ }^{33}$

This is not to say that appeals to theoretical virtue cannot be used to support less ambitious claims. Lewis (1986) appeals to simplicity when he argues that certain rival views are problematically committed to primitive modality. All other things equal, if a rival view is committed to primitive modality that his view can do without, then his view is to be preferred. This is a far cry from the claim that primitive modality should be avoided at all costs. Some costs are too high. After all, it is a common refrain that Lewis's modal realism should be rejected for its ontological extravagance, despite its promise of ideological simplicity.

\section{Starting points}

I have argued that the direct and indirect routes to FEMF do not provide independent motivation for FEMF. While this is not a refutation of the thesis, it shows that FEMF is currently not well motivated. This is a problem for those who appeal to FEMF in the course of their arguments. Schaffer (2010a) explicitly uses FEMF as a premise in his argument for priority monism, the view that the whole (concrete) universe is more fundamental than its parts. Bennett (Forthcoming) invokes FEMF in an argument against the possibility of genuinely indeterministic building, where her building relation takes us from the fundamental to the nonfundamental. ${ }^{34}$ And those who invoke the ideology of naturalness typically hold that the perfectly natural properties form a minimal supervenience base, so that no perfectly natural properties supervene on any others. ${ }^{35}$ This may be construed as an endorsement of FEMF, for supervenience is a modal notion.

The defender of FEMF may regard my arguments above as irrelevant, for she may think that no sensible defender of FEMF thinks there are good independent reasons to adopt FEMF anyway. She may point out that we must all accept certain starting points in metaphysical theorizing. I would thus like to end by considering the question of starting points in metaphysical theorizing. This is not a topic on which I have a settled opinion. It is a tremendously difficult question. And I am happy to acknowledge because metaphysicians must start somewhere, some may reasonably find themselves starting with FEMF. What I have tried to do in this paper is show that, on reflection, the positive reasons for FEMF are either themselves problematic, or come down to mere intuition. And if it is mere intuition, then it is not clear that FEMF is a better starting point than others. This is all I mean to have shown - the remainder of this section is merely suggestive.

First of all, not all fundamentality theorists endorse FEMF. Sider's (2011) structural entities, which include predicates and quantifiers, must fit together in certain ways. Wilson (2012) allows both fundamental determinables and determinates, and these must be related to each other in certain ways. And Fine's (2001) real propositions may stand in grounding relations to each other. There is conceptual space between ontological independence and modal independence, according to many. I think that this separation is valuable and should be preserved.

\footnotetext{
33 Perhaps those who hold 'systematic' views that have broad scope across philosophical topics are closest.

${ }^{34} \mathrm{In}$ fact, FEMF is invoked in a number of places in Bennett (Forthcoming). See for instance her section 6.2, 7.2, and 8.2.3.

35 Eddon (2009) argues against this thesis.
} 
Second, starting with FEMF closes too many doors. One may be led to a view incompatible with FEMF - such as those mentioned in section 1-by following a general strategy of looking to physics to provide one's fundamental ontology. This strategy just happens to result in the view that there are fundamental entities that are determinates of the same determinate, or essentially causal, etc. FEMF rules out such views from the start. We ought not accept a thesis that from the start rules out views that result from the methodology of looking to physics to provide one's fundamental ontology. This is a prima facie reason to reject FEMF.

The same point can be made using historical examples. For instance, the notion of substance in the history of western philosophy is arguably a notion of fundamentality. ${ }^{36}$ Yet FEMF seems to be incompatible many of these views, for many hold that the existence of finite substances is modally dependent upon the existence of God. For another example, it is arguably the case that for Plato, the Form of the Good is fundamental, yet there are necessary connections between Good and the other Forms. ${ }^{37}$ In contrast, Democritus's atoms arguably form the basis of a combinatorial theory of possibility. These atoms have only what are called 'primary qualities' in the seventeenth century: size, shape, position, solidity, etc. ${ }^{38}$ There is a rich history behind us, and it should be properly assessed in the context of our contemporary debates about fundamentality and related notions.

* Many thanks to Elizabeth Barnes, Ross Cameron, Michael Della Rocca, Tom Donaldson, Nina Emery, Martin Glazier, Li Kang, Michaela McSweeney, Carla Merino, Daniel Nolan, Amy Seymour, Christina Van Dyke, Jessica Wilson, and audiences at the 2015 Pacific APA, the 2015 New Directions in Modality Conference at Humboldt University, the 2016 Ranch Metaphysics Conference, and Santa Clara University.

\section{Bibliography}

Armstrong, David M. 1989. A Combinatorial Theory of Possibility. New York: Cambridge University Press.

- 1997. A World of States of Affairs. Cambridge: Cambridge University Press. . 2004. Truth and Truthmakers. Cambridge: Cambridge University Press.

Audi, Paul. 2012a. "A Clarification and Defense of the Notion of Grounding." In Metaphysical Grounding: Understanding the Structure of Reality, edited by Fabrice Correia and Benjamin Schnieder, 101-121. Cambridge: Cambridge University Press.

- 2012b. "Grounding: Toward a Theory of the In-Virtue-Of Relation." Journal of Philosophy 109/12: 685-711.

Barnes, Elizabeth. 2012. “Emergence and Fundamentality.” Mind, 121/484: 873-901.

\footnotetext{
${ }^{36}$ Kathrin Koslicki has a number of interesting papers on ontological dependence, substancehood, and essence, with a focus on neo-Aristotelian theories. See Koslicki (2013a, 2013b).

37 Useful resources include Shorey (1980) and Vlastos (1981). I am indebted to Christina Van Dyke for this and the next example, though she is not to be held responsible for my brutish descriptions of these views. 38 Useful resources include Curd (1998) and Mouralatos (2004), though see Pasnau (2007).
} 
_. Forthcoming. "Symmetric Dependence." In Reality and Its Structures, edited by Ricki Bliss and Graham Priest. Oxford University Press.

Bennett, Karen. 2011a. "By Our Bootstraps." Philosophical Perspectives 25/1: 27-41.

79-104.

- Forthcoming. Making Things Up. Oxford University Press.

Bigelow, John. 1988. The Reality of Numbers: A Physicalist's Philosophy of Numbers, Oxford: Oxford University Press.

Bird, Alexander. 2007. Nature's Metaphysics: Laws and Properties. Oxford: Oxford University Press.

Cameron, Ross. 2008. "Truthmakers and Ontological Commitment: or How to Deal with Complex Objects and Mathematical Ontology without Getting into Trouble." Philosophical Studies, 140: 1-18.

—. 2010a. "From Humean Truthmaker Theory to Priority Monism." Noûs 44/1: 178198.

2010b. "How to Have a Radically Minimal Ontology." Philosophical Studies, 151/2: 249-264.

Clark, Michael J. and David Liggins. 2012. "Recent Work on Grounding." Analysis 72: 812823.

Correia, Fabrice. 2010. "Grounding and Truth-Functions." Logique Et Analyse 53/211: 251279.

Correia, Fabrice and Benjamin Schnieder. 2012. "Grounding: An Opinioned Introduction." In Metaphysical Grounding: Understanding the Structure of Reality, edited by Fabrice Correia and Benjamin Schnieder, 1-36. Cambridge: Cambridge University Press.

Dasgupta, Shamik. 2009. "Individuals: An Essay in Revisionary Metaphysics." Philosophical Studies 145/1: 35-67.

deRosset, Louis. 2009. "Production and Necessity." Philosophical Review 118/2:153-181.

—. 2010. "Getting Priority Straight." Philosophical Studies 149/1: 73-97. . 2013. "Grounding Explanations." Philosophers' Imprint 13/7: 1-26.

Donaldson, Thomas. Forthcoming. "The (Metaphysical) Foundations of Arithmetic?" Noûs.

Dorr, Cian and Hawthorne, John. 2013. "Naturalness." Oxford Studies in Metaphysics, Volume

8, Bennett, edited by Karen Bennett and Dean Zimmerman, 3-77. Oxford: Oxford University Press.

Eddon, Maya. 2013. "Fundamental Properties of Fundamental Properties." In Oxford Studies in Metaphysics, Volume 8, edited by Karen Bennett and Dean Zimmerman, 78-104. Oxford: Oxford University Press.

Fine, Kit. 1994. "Essence and Modality." Philosophical Perspectives 8: 1-16.

— 1995. "Ontological Dependence." Proceedings of the Aristotelian Society 95: 269290.

—. 2001. "The Question of Realism." Philosophers' Imprint 1/1: 1-30. . 2012. "Guide to Ground." In Metaphysical Grounding: Understanding the Structure of Reality, edited by Fabrice Correia and Benjamin Schnieder, 37-80. Cambridge: Cambridge University Press.

Fox, John F. 1987. "Truthmaker.” Australasian Journal of Philosophy 65/2: 188-207. Ismael, Jenann. and Schaffer, Jonathan. Forthcoming. "Quantum Holism: Nonseparability as Common Ground." Synthese. 
Jenkins, Carrie. 2011. “Is Metaphysical Dependence Irreflexive?” The Monist 94/2: 267-276. Jubien, Michael. 2009. Possibility. Oxford: Oxford University Press.

Kleinschmidt, Shieva. 2015. "Fundamentality and Time-Travel." Thought 4/1: 46-51.

Kment, Boris. 2014. Modality and Explanatory Reasoning. Oxford: Oxford University Press.

Koslicki, Kathrin. 2013a. “Ontological Dependence: An Opinionated Survey." In Varieties of

Dependence: Ontological Dependence, Grounding, Supervenience, Response-Dependence, edited by Benjamin Schnieder, Miguel Hoeltje, and Alex Steinberg, 31-64. München: Philosophia Verlag.

- 2013b. "Substance, Independence, and Unity." In Aristotle on Method and Metaphysics, edited by Edward Feser, 169-195. Basingstoke, UK: Palgrave/MacMillan.

Lewis, David. 1983. "New Work for a Theory of Universals." Australasian Journal of Philosophy 61/4: 343-377.

- 1986a. On the Plurality of Worlds. Oxford: Blackwell Publishing.

—. 1986b. Philosophical Papers, Volume II. Oxford: Oxford University Press.

Litland, Jon E. 2013. "On Some Counterexamples to the Transitivity of Grounding." Essays in Philosophy 14/1: 19-32.

Lowe, E.J. 2006. The Four-Category Ontology: A Metaphysical Foundation for Natural Science. Oxford: Oxford University Press.

Lowe, E.J. 2009. "An Essentialist Approach to Truth-Making." In Truth and Truth-Making, edited by E.J. Lowe and A. Rami, 201-216. Stocksfield: Acumen.

Mulligan, Kevin, Peter Simons, and Barry Smith. 1984. "Truth-makers." Philosophy and Phenomenological Research 44: 287-321.

Pasnau, Robert. 2007. "Democritus and Secondary Qualities." Archiv für Geschichte der Philosophie 89/2: 99-121.

Paul, L.A. 2012. "Building the World From Its Fundamental Constituents." Philosophical Studies 158/2: 221-256.

—. Forthcoming. "Mereological Bundle Theory." In Handbook of Mereology, edited by H. Burkhardt, J. Seibt, and G. Imaguire. Philosophia Verlag.

Quine, W.V. 1970. The Web of Belief. New York: Random House.

Robinson, Denis. 1993. "Epiphenomenalism, Laws and Properties." Philosophical Studies 69: 1-34.

Raven, Michael. 2013. "Is Ground a Strict Partial Order?” American Philosophical Quarterly 50/2: 193-201.

Rodríguez-Pereyra, Gonzalo. 2006a. "Truthmakers." Philosophy Compass, 1/2: 186-200.

- 2006b. "Truthmaking, Entailment, and the Conjunction Thesis." Mind 115: 957982.

—. 2015. "Grounding is not a Strict Order." Journal of the American Philosophical Association 1/3: 517-534.

Rosen, Gideon. 2010. "Metaphysical Dependence: Grounding and Reduction." In Modality: Metaphysics, Logic, and Epistemology, edited by Bob Hale and Aviv Hoffmann, 109-135. Oxford: Oxford University Press.

Schaffer, Jonathan. 2003. "The Problem of Free Mass: Must Properties Cluster?" Philosophy and Phenomenological Research 66/1: 125-138.

—. 2008. "Truthmaker Commitments." Philosophical Studies 141/1: 7-19.

—. 2010a. "The Internal Relatedness of All Things." Mind 119/474: 341-36. 
_ 2010b. "The Least Discerning and Most Promiscuous Truthmaker." Philosophica Quarterly 69/239: 307-324.

—. 2010c. "Monism: The Priority of the Whole." Philosophical Review 119/1: 31-76. - 2012. "Grounding, Transitivity, and Contrastivity." In Metaphysical Grounding: Understanding the Structure of Reality, edited by Fabrice Correia and Benjamin Schnieder, 122-138. Cambridge: Cambridge University Press.

Schnieder, Benjamin. 2006. "Truth-making without Truth-makers." Synthese 152/1: 21-46. Shoemaker, Sydney. 1980. "Causality and Properties." In Time and Cause, edited by Peter van Inwagen, 228-254. Dordrecht: D. Reidel.

Shorey, Paul. 1980. "Idea of Good in Plato's Republic." Selected Papers, Volume II, 28-79. New York: Garland.

Sider, Theodore. 2011. Writing the Book of the World. Oxford: Oxford University Press. Skiles, Alexander. 2015. “Against Grounding Necessitarianism." Erkenntnis 80/4: 717-751. Trogdon, Kelly. 2013a. "An Introduction to Grounding." In Varieties of Dependence: Ontological Dependence, Grounding, Supervenience, Response-Dependence, edited by Benjamin Schnieder, Miguel Hoeltje, and Alex Steinberg, 97-122. München: Philosophia Verlag.

_. 2013b. "Grounding: Necessary or Contingent?" Pacific Philosophical Quarterly 94/4: 465-485.

Vetter, Barbara. 2011. "Recent Work: Modality Without Possible Worlds." Analysis, 71/4: 742-754.

- 2015. Potentiality: From Dispositions to Modality. Oxford: Oxford University Press.

Vlastos, Gregory. 1981. "Degrees of Reality in Plato." Platonic Studies, $2^{\text {nd }}$ Edition, 58-75. Princeton: Princeton University Press.

Wang, Jennifer. 2013. "From Combinatorialism to Primitivism." Australasian Journal of Philosophy 91/3: 535-554.

Weatherson, Brian. 2006. "The Asymmetric Magnets Problem." Philosophical Perspectives 20: 479-492.

- 2013. "The Role of Naturalness in Lewis's Theory of Meaning." Journal for the History of Analytical Philosophy, 1/10: 1-19.

_. 2014. "David Lewis." In The Stanford Encyclopedia of Philosophy (Winter 2014 Edition), edited by E. Zalta. URL = <http://plato.stanford.edu/archives/win2014/entries/david-lewis/>.

Wilson, Jessica. 2010. "What is Hume's Dictum, and Why Believe It?" Philosophy and Phenomenological Research 80/3: 595-637.

—. 2012. "Fundamental Determinables." Philosophers' Imprint 12/4: 1-17. . 2014a. "Hume's Dictum and the Asymmetry of Counterfactual Dependence." In Chance and Temporal Asymmetry, edited by Alastair Wilson, 258-279. Oxford: Oxford University Press.

—. 2014b. "No Work for a Theory of Grounding." Inquiry 57/5-6: 535-579. . 2015. "Hume's Dictum and Metaphysical Modality: Lewis's Combinatorialism." In $A$ Companion to David Lewis, edited by Barry Loewer and Jonathan Schaffer, 138-158. Wiley-Blackwell.

Wittgenstein, Ludwig. 1921/1961. Tractatus Logico-Philosophicus, translated by D.F. Pears and B.F. McGuinness. New York: Humanities Press. 
Zimmerman, Dean. Forthcoming. "A Recent Defense of Monism Based Upon the Internal Relatedness of All Things." In The Metaphysics of Relations, edited by F. Clementz and J.M. Monnoyer. Ontos Verlag. 